\title{
Investigating the use of mastery-style online homework exercises in introductory algebra-based mechanics in a controlled clinical study
}

\author{
William R. Evans and Mats A. Selen \\ Department of Physics, University of Illinois at Urbana-Champaign, \\ 1110 West Green Street, Urbana, Illinois 61801-3003, USA
}

(Received 28 November 2016; published 4 October 2017)

\begin{abstract}
Homework in introductory physics represents an important part of a student's learning experience; therefore, choosing the manner in which homework is presented merits investigation. We performed three rounds of clinical trials comparing the effects of mastery-style homework vs traditional-style homework with students in both algebra-based and calculus-based introductory mechanics. Results indicate a benefit from mastery-style over traditional-style homework, principally for weaker students who are less familiar with the material being covered and on questions that are nearer transfer to the study materials.
\end{abstract}

DOI: 10.1103/PhysRevPhysEducRes.13.020119

\section{INTRODUCTION}

Homework represents a significant part of a student's learning resources in many introductory physics classes, so optimizing the pedagogy of online homework delivery is an important goal of education research. Various options for homework delivery have been investigated for their effects on student learning, and one approach of particular interest is the mastery method of learning pioneered by Bloom in the 1960s [1].

The mastery method is a cycle of formative assessment followed by additional learning opportunities. When a student completes a series of homework problems, correctness feedback is given on the set of problems as a whole. If the student reaches a certain correctness threshold (often $100 \%$ ), the student is considered to have mastered the material and is permitted to move on to the next section or topic. If the student does not master the material, he or she is given additional learning opportunities to help improve his or her understanding. These additional learning opportunities are followed by a similar set of homework problems on the same material. This cycle continues until the student has achieved mastery.

Although Bloom is usually credited for outlining the mastery method of learning, other educators have advanced similar methods. One such method was Keller's "personalized system of instruction" [2]. Both of these methods center on repeated testing with additional learning opportunities as needed. Bloom's and Keller's methods were inspired by psychological principles which today are understood in terms of the testing effect [3-5] and

Published by the American Physical Society under the terms of the Creative Commons Attribution 4.0 International license. Further distribution of this work must maintain attribution to the author(s) and the published article's title, journal citation, and DOI. formative assessment [6], both of which have been shown to improve student learning.

Mastery-inspired homework has not only been established theoretically, but it has also been validated experimentally in several different course settings. Various authors have published meta-analyses of Bloom's and Keller's systems of learning. Some of the primary results that were observed included improvement over traditional instruction on immediate performance, closing achievement gaps, and improved student attitudes and selfconfidence [7-13].

Inspired by the potential benefit of mastery-style homework, the physics education research group at the University of Illinois ran a series of clinical studies testing the effects of mastery-inspired homework in an introductory electricity and magnetism course for physics and engineering majors. Gladding et al. [14] compared computer-based mastery-style homework with a more traditional computer-based homework format currently used in the introductory physics classes at the University of Illinois. This traditional format involves immediate correctness feedback and an unlimited number of attempts. In the Gladding et al. study, students who completed homework presented in the mastery style significantly outperformed students who completed the same homework presented in the more traditional style on a post-test covering the topics that the students studied in the homework.

Motivated by the positive effects of mastery-style homework observed in the above studies, the primary goal of this study was to investigate whether this pedagogy would have a similar effect on students in an algebra-based introductory physics class which primarily serves life science majors. The question of how best to teach physics to life science students has been a topic of conversation for decades, and has resulted in various types of reformed Introductory Physics for Life Science (IPLS) courses at different institutions (see Refs. [15-19] for some representative 
reforms). While most studies of reformed IPLS courses have focused on the content being taught in the course, the study we present in this paper focused on the pedagogy by which that content is delivered.

\section{OVERVIEW OF CLINICAL TRIALS}

The goal of this experiment was to evaluate the effectiveness of computer-based mastery-inspired homework for learning in introductory mechanics in a controlled clinical setting. Three clinical trials were run in this experiment, and a summary of the different trials is given in Table I. In each trial, participating students were randomly divided into two groups, where one group received a series of homework problems in the traditional format described above, and the other group received the same series of homework problems in the mastery format.

Students in this experiment were enrolled either in the algebra-based College Physics: Mechanics and Heat or in the calculus-based University Physics: Mechanics courses at the University of Illinois at Urbana-Champaign. The algebra-based course is required for many of the life science majors on campus, and most of the students in this course are juniors and seniors. The calculus-based course is the first in a sequence of introductory physics courses required for physics and engineering majors at the university. It is generally taken during the freshman year of a student's college career.

No course credit was offered to students for participating in these experimental trials. Rather, these trials were advertised as a means of helping students prepare for an upcoming exam, and students were told that they would receive extra office hour help from experienced TAs after the experiment.
The differences in the homework conditions seen by the two groups are summarized in Table II.

In the mastery-style homework condition, students were presented with sets of four or five questions on a given topic. Once all the questions in a set were completed, the student submitted these questions to be graded, and correctness feedback was given. At this point, the students had access to narrated, animated solution videos to the problems they had just completed. These solution videos constituted the additional learning opportunities outlined in the description of the mastery method of learning. These videos were designed to walk students through the steps used in solving the problems. The goal of these videos was to help the students complete subsequent problem sets on the same topic. If a student completed all of the questions in the problem set correctly, he or she was said to have mastered the topic of that problem set and was permitted to move on to the next topic. If a student did not complete all the questions in the problem set correctly, he or she was then presented with an equivalent problem set on the same topic. The problems in these subsequent sets were designed to be similar, but not identical, to the original problem set. This cycle continued until the student completed all the questions in a problem set correctly. Because students in the mastery-style homework condition had to complete an entirely new set if any question was answered incorrectly, mastery-style questions were given in a multiple-choice format to help students catch minor errors and minimize the resulting student frustration.

In the traditional-style homework condition, students had access to all the topics simultaneously, so questions could be completed in any order. Students received correctness feedback on their answers after each submission. An

TABLE I. Summary of the three clinical trials.

\begin{tabular}{|c|c|c|c|c|c|c|}
\hline Trial & Course & Topic & Timing & $\begin{array}{c}\text { Total } \\
\text { participants }\end{array}$ & $\begin{array}{l}\text { Traditional-homework } \\
\text { participants }\end{array}$ & $\begin{array}{l}\text { Mastery-homework } \\
\text { participants }\end{array}$ \\
\hline 1 & Algebra-based Mechanics & Friction & Prior to first midterm & 31 & 15 & 16 \\
\hline 2 & Calculus-based Mechanics & Friction & Prior to first midterm & 31 & 15 & 16 \\
\hline 3 & Algebra-based Mechanics & $\begin{array}{c}\text { Newton's laws } \\
\text { of motion }\end{array}$ & Prior to final exam & 49 & 19 & 30 \\
\hline
\end{tabular}

TABLE II. Summary of different homework conditions.

\begin{tabular}{|c|c|c|}
\hline & Traditional homework condition & Mastery homework condition \\
\hline Presentation of topics & All topics available simultaneously & $\begin{array}{l}\text { Topics presented sequentially in } \\
\text { problem sets of four or five questions each }\end{array}$ \\
\hline Question type & Free response & Multiple choice \\
\hline Feedback type & $\begin{array}{l}\text { Immediate correctness feedback } \\
\text { after each question submission }\end{array}$ & $\begin{array}{l}\text { Correctness feedback given after } \\
\text { submitting a set of questions }\end{array}$ \\
\hline Learning assistance & $\begin{array}{l}\text { Students encouraged to use notes } \\
\text { and work with peers }\end{array}$ & $\begin{array}{l}\text { Narrated, animated solution videos } \\
\text { given after completing a problem set }\end{array}$ \\
\hline
\end{tabular}


unlimited number of submissions were allowed for each question. The problem sets viewed by the students in the traditional-style homework condition were the initial problem sets on each topic viewed by the students in the mastery-style homework condition. Since students in this group had immediate correctness feedback and an unlimited number of tries, the traditional-style homework problems were presented as free-response questions rather than multiple choice. To balance the additional help that the students in the mastery-style homework condition received from the solution videos, students doing homework problems in the traditional style were encouraged to use course notes and to work with each other in completing their problem sets. These resources are similar to those a student might use when doing their regular homework in the course.

After students in both groups completed the homework problems, they were given a paper-based free-response post-test on the same topics covered in the homework problems. Each of the twelve questions on the post-test was graded out of three points by two different graders. In cases where the scores given by the two graders differed by more than 1 point, the student's response was revisited and discussed by both graders until a consensus could be reached. The average of the scores given by the two graders on each problem was used in the subsequent analysis.

\section{FIRST CLINICAL TRIAL}

The first trial involved students from algebra-based physics and was run shortly before the students' first midterm exam (see Table I). Figure 1 shows the scores from each group on each of the twelve questions on the post-test.

We used the students' first midterm exam as a post hoc control to make sure that one homework condition group did not have an inherently higher physics ability than the other. The difference in midterm scores between the two homework condition groups was not judged to be significant ( $p>0.10$ by either a one-tail or two-tail student $t$ test). We took this similarity in scores as evidence that the inherent physics abilities of the students in the two homework condition groups were similar. We therefore concluded that differences in performance on the clinical trial's post-test could be primarily attributed to the style of homework problems that the students worked on during the clinical trial.

On average, students in the mastery-homework condition outperformed students in the traditional-homework condition on 9 of the 12 questions on the post-test, significantly so on 3 of them with another one being marginally significant, and with an effect size of at least 0.6 on each. These were question 1 ( $p=0.005$ on a one-tail $t$ test, $p=$ 0.010 on a two-tail $t$ test, with a Cohen's $d$ effect size of 1.0 ), question 4 ( $p=0.035$ one-tail, $p=0.07$ two-tail, effect size 0.7 ), question 8 ( $p=0.004$ one-tail, $p=0.008$

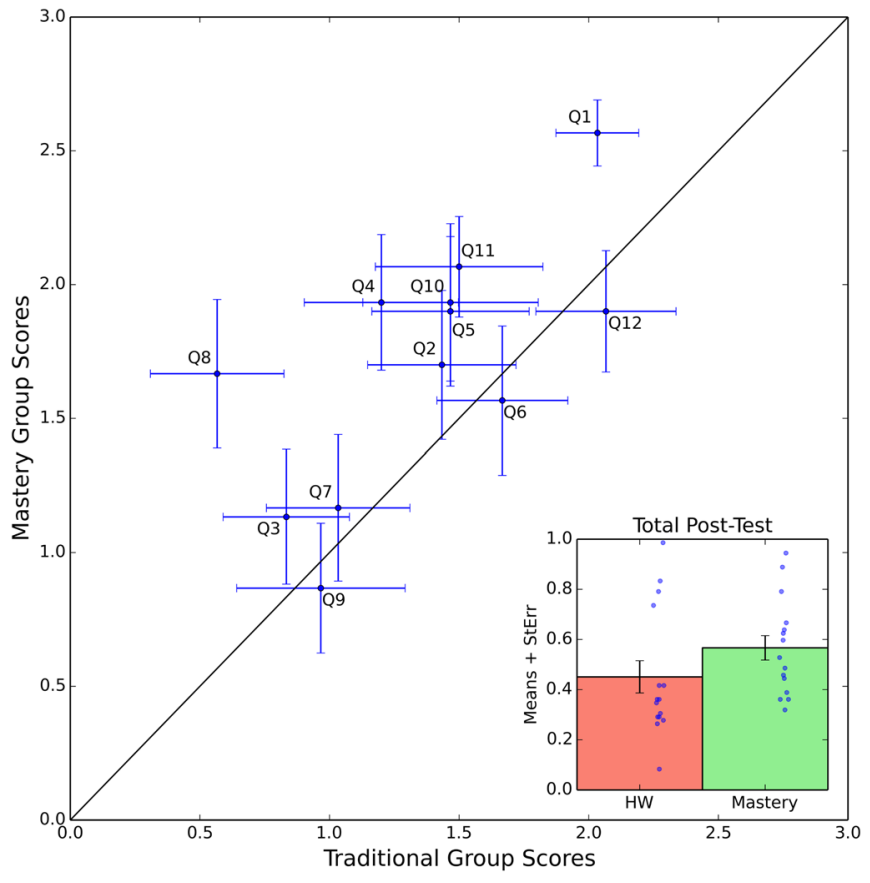

FIG. 1. Normalized average scores on each of the twelve questions on the post-test used in the first clinical trial. Average scores with standard errors for students in the mastery-homework condition are plotted on the vertical axis, and average scores with standard errors for students in the traditional-homework condition are plotted on the horizontal axis. Points appearing above the diagonal line indicate questions on which the students in the mastery-homework condition outperformed students in the traditional-homework condition. Inset: Normalized total average scores on the post-test with standard errors are shown for the two homework conditions. Dots on the inset graph represent individual students' total scores. Compare Fig. 4 from Ref. [14].

two-tail, effect size 1.0), with question 11 being marginally significant ( $p=0.055$ one-tail, $p=0.11$ two-tail, effect size 0.6); see Fig. 1. There were no questions on the posttest on which the students in the traditional-homework condition significantly outperformed the students in the mastery-homework condition. The post-test questions on which the students in the mastery-homework condition most significantly outperformed the students in the traditional-homework condition appeared to be those that were most similar to the homework questions.

To test the hypothesis that a problem's nearness of transfer was correlated with the two groups' difference in performance on that problem, we decided to analyze the nearer and farther transfer questions on the post-test separately. As degree of transfer is notoriously difficult to quantify, we presented the post-test and the homework from the clinical study to several members of the physics education research group at the University of Illinois. These eight experts rated the post-test questions on a scale of 0 to 5 by how near or far transfer they judged the questions to be from the homework problems. Their responses were 


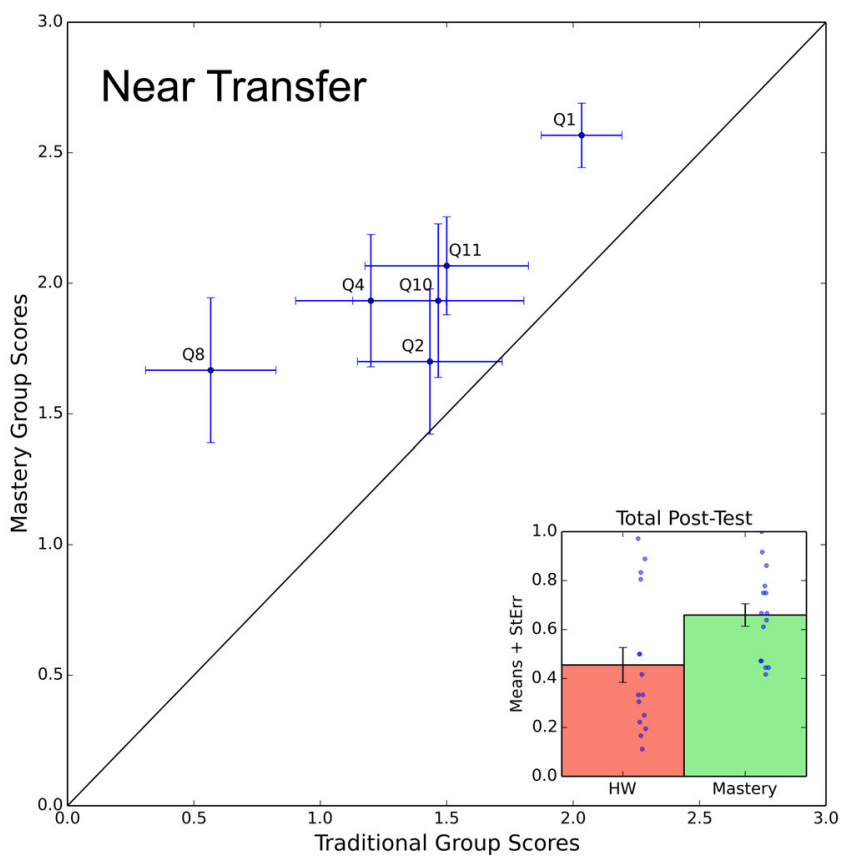

(a)

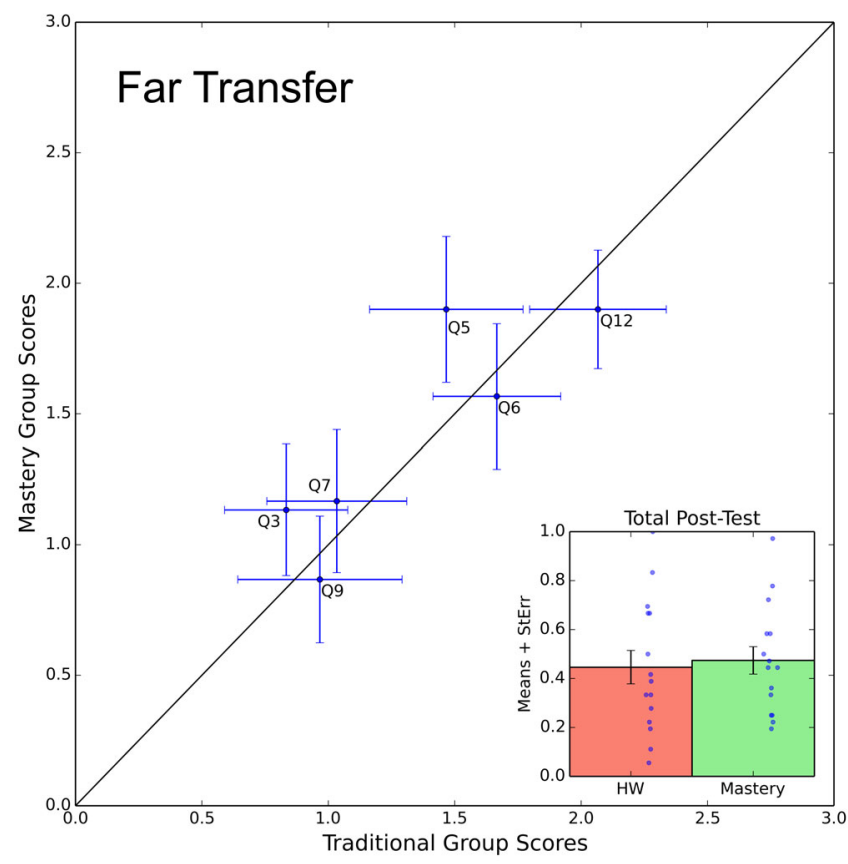

(b)

FIG. 2. Performance of students in the first clinical trial, with nearer- and farther-transfer questions analyzed separately. (a) Performance of students on those post-test questions which were judged to be nearer-transfer to the homework problems. As seen on the inset graph, the difference in total scores between the mastery and traditional homework groups was judged to be significant with $p=0.009$ ( $p=0.018$ two-tail $t$-test) and a Cohen's d effect size of 0.9. (b) Performance of students on those post-test questions which were judged to be farther-transfer to the homework problems. As seen on the inset graph, the difference in total scores between the mastery and traditional homework groups was not significant.

averaged, and the questions were split into two equal-sized groups representing those problems with nearer or farther degrees of transfer. The results are shown in Fig. 2. Note that these experts did not have access to the students' performance data when making judgements about nearness of transfer. As we had such close familiarity with the questions, both in the homework and in the post-test, and with the students' performance on each of the questions, neither of us was included among the experts rating nearness of transfer.

Figure 2(a) shows that the students in the masteryhomework condition significantly outperformed the students in the traditional-homework condition on the nearer-transfer questions from the post-test. As discussed previously, this difference in performance was significant on 3 of the 6 questions (questions 1, 4, and 8), and marginally significant on another one (question 11). On each of these questions where the difference was significant or marginally significant, the effect size was at least 0.6. The difference in overall performance between homework condition groups on these six nearer-transfer questions was significant with $p=0.009$ ( $p=0.018$ two-tail $t$ test) and with an effect size of 0.9 . The difference in performance between students in the two homework conditions was not judged to be significant on any of the six farther-transfer questions [see Fig. 2(b)].
In addition, we analyzed the effects of mastery-style homework on the stronger and weaker students in each group separately. Figure 3 shows the performance of students in the top and bottom half of each homework condition group, as measured by their final semester course scores. As can be seen in Fig. 3(a), the difference in posttest performance between the mastery-homework group and the traditional-homework group is highly significant for the weaker students. Weaker students in the masteryhomework condition significantly outperformed the weaker students in the traditional-homework condition on the posttest ( $p<0.05$ on a one-tail $t$ test). For comparison, Fig. 3(b) shows that the stronger students in each homework condition performed almost identically on the post-test.

\section{SECOND AND THIRD CLINICAL TRIALS}

The second trial involved students from calculus-based physics and was run shortly before the first midterm exam (see Table I). We used the same materials that were used in the first trial with the students in algebra-based mechanics, which allowed us to directly compare the performance of the students in the two classes. Students in the calculusbased class demonstrated higher proficiency with problems involving friction, in that their average scores on the posttest were higher $(74 \% \pm 3 \%)$ than the students in the algebra-based course $(50 \% \pm 4 \%)$. 


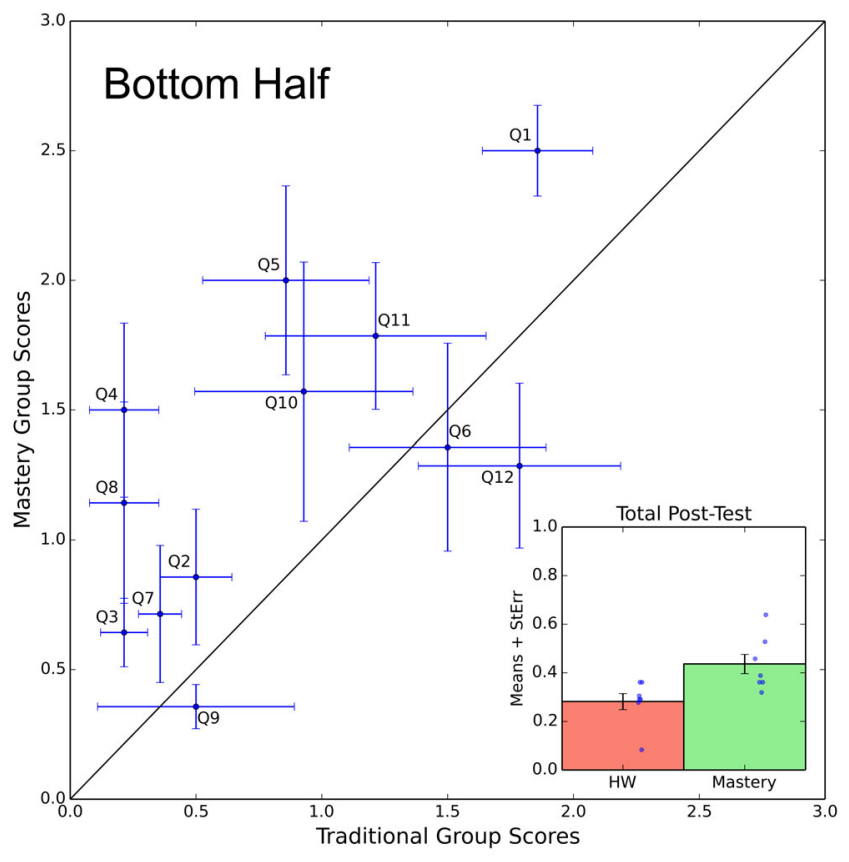

(a)

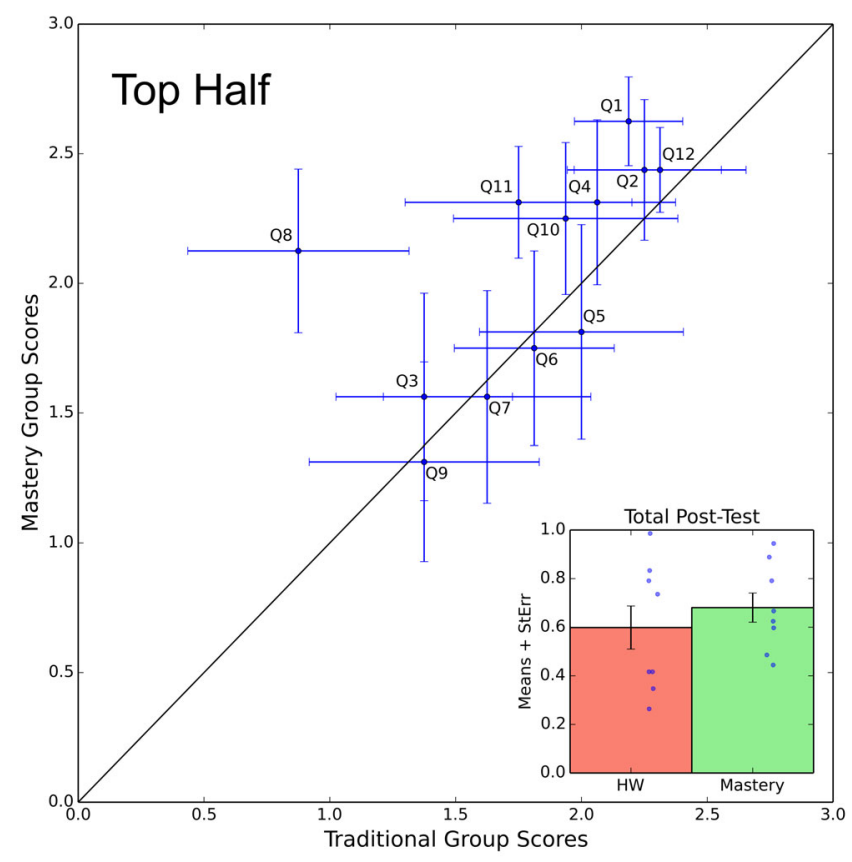

(b)

FIG. 3. Performance of students in the first clinical trial with students in the top and bottom half of each homework condition group analyzed separately. This median split was performed using the students' final semester course scores. Dots on the inset graphs show individual student post-test totals. (a) Performance of students in the bottom half of each homework condition group as measured by their final semester course scores. The difference in post-test total scores is significant with $p<0.05$ on a one-tail $t$-test. (b) Performance of students in the top half of each homework condition group as measured by their final semester course scores. The difference in posttest total scores is not significant.

In this trial, no difference was seen when comparing students in the mastery-homework condition with the students in the traditional-homework condition. Student performance on the post-test in the second trial is shown in Fig. 4(a).

The third trial involved students from algebra-based physics and covered the subject of Newton's laws of motion (see Table I). This trial was run shortly before the final exam, by which point the students had been using Newton's laws for most of the semester. No difference was seen when comparing students in the mastery-homework condition with the students in the traditional-homework condition in this trial. Student performance on the post-test in the third trial is shown in Fig. 4(b).

\section{DISCUSSION}

The results of the first clinical trial show that the mastery-style homework approach can have a positive impact on students in algebra-based physics. Although our statistics were limited, significant differences between the two different groups were seen on near-transfer problems and for students least proficient with the material.

The results of the second clinical trial, in which engineering and physics majors were given the same materials used with the life science majors in the first trial, showed no difference between the two homework conditions. The results of the third clinical trial, which was given at the end of the semester and which focused on Newton's laws of motion, also showed no difference between the two groups. Both of these results are consistent with the hypothesis that students already proficient with the material benefit less from mastery-style homework than students that are initially less proficient with the material. The uncertainties, however, are too large to make a significant claim.

While further work is needed to verify the effects of mastery-style homework on learning in introductory physics, our results show that mastery-style homework appears to benefit some students in introductory mechanics over traditional-style homework. This effect is most significant with students who are weaker or less familiar with the material, or when the degree of transfer between the learning materials and the testing materials is small, hence further work in this area would likely see the most significant effects when focusing on these conditions. While the results we present are promising, we are cautioned by the fact that our study involved students in controlled clinical trials, and further work is needed to see how well these results transfer into an actual classroom setting.

While there is likely no "silver bullet" to help students overcome all the difficulties in learning physics, these 


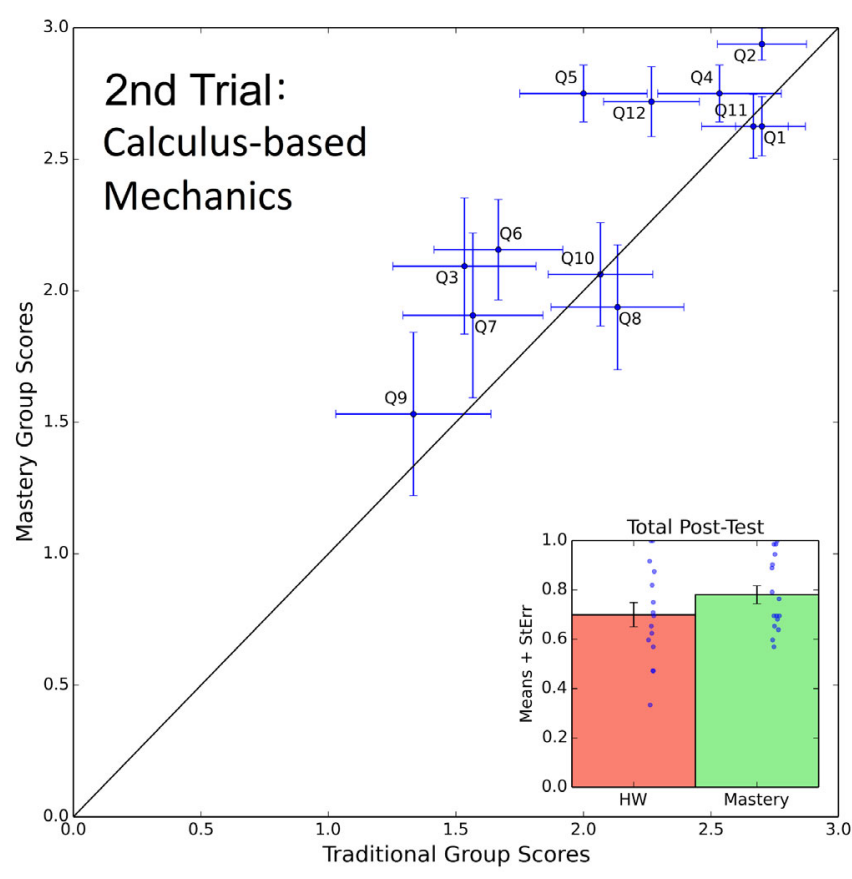

(a)

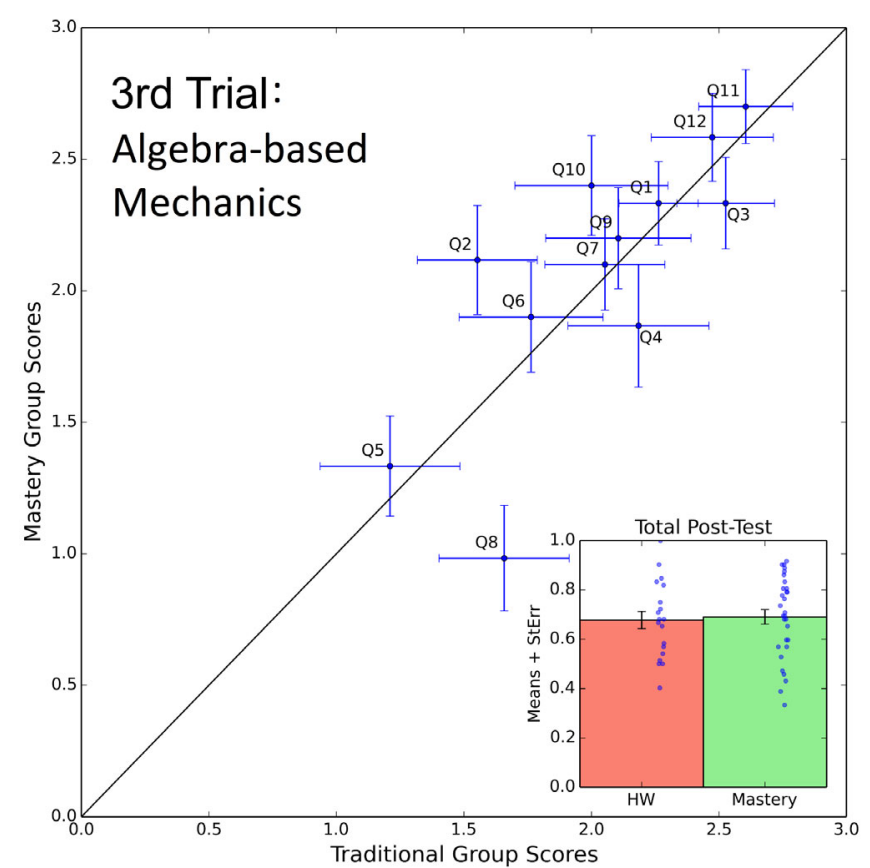

(b)

FIG. 4. Performance of students in the second and third clinical trials. Average scores with standard errors for students in the masteryhomework condition are plotted on the vertical axis, and average scores with standard errors for students in the traditional-homework condition are plotted on the horizontal axis. Average total scores for the students in each homework condition are shown in the inset. Dots on the inset graphs show individual student post-test totals. (a) Performance of students in the second clinical trial. This trial involved students in calculus-based physics and covered the topic of friction, using the same materials as the first clinical trial. This trial was run before the first midterm in the course. The difference in total scores is not significant. (b) Performance of students in the third clinical trial. This trial involved students in algebrabased physics and covered the topic of Newton's laws. The clinical trial was run before the course's comprehensive final exam. The difference in total scores is not significant.

results indicate that appropriately used mastery-style homework activities can help students better master the skills needed in algebra-based introductory mechanics.

\section{ACKNOWLEDGMENTS}

This work was partially funded by a grant from the Strategic Instructional Innovations Program at the University of Illinois. The authors would also like to thank the University of Illinois Physics Education Research Group, especially Brianne Gutmann and Elaine Schulte for particularly helpful conversations and editing.

\section{APPENDIX A: FRICTION POST-TEST}

This post-test was used with clinical trials 1 and 2 (see Table I).

(1) Three blocks (with masses $M 1, M 2$, and $M 3$ ) are arranged on a frictionless table as shown (see Fig. 5). A horizontal force $F$ is applied as shown. The coefficient of static friction between $M 2$ and $M 3$ is $\mu_{S}$, and $M 3$ does not slip on $M 2$. Draw a free-body diagram for $M 2$.

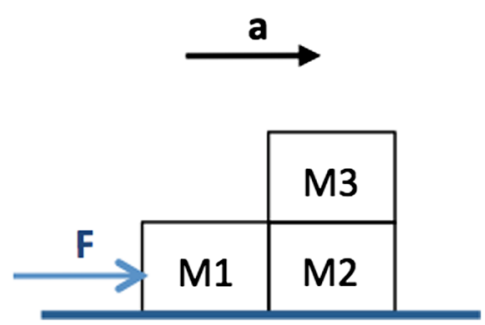

FIG. 5. Figure for friction post-test problem 1.

(2) An $8 \mathrm{~kg}$ block is pulled across a horizontal surface by a horizontal rope (see Fig. 6). The tension in the rope is $50 \mathrm{~N}$, and the acceleration of the block is $2.5 \mathrm{~m} / \mathrm{s}^{2}$. What is the coefficient of kinetic friction between the block and the surface? (Please show your work.)

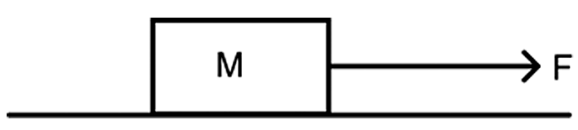

FIG. 6. Figure for friction post-test problem 2. 


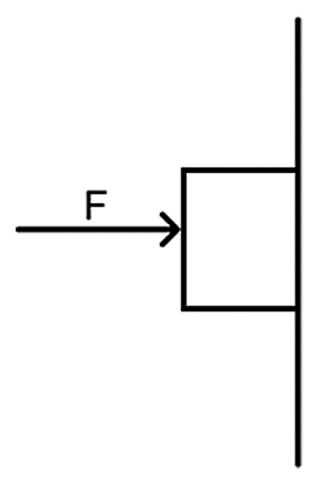

FIG. 7. Figure for friction post-test problem 3.

(3) Suppose you push a book horizontally against a wall and friction keeps the book from sliding downward, as shown in the picture (see Fig. 7). The weight of the book is $12 \mathrm{~N}$, and the magnitude horizontal force you apply is $30 \mathrm{~N}$. The coefficient of static friction between the book and the wall is $\mu_{S}=0.667$. What is the magnitude of the frictional force exerted on the book by the wall? Assume your hand does not provide any vertical force. (Please show your work.)

(4) [The following two questions refer to the same physical situation.] A block of mass $M=$ $6 \mathrm{~kg}$ slides down an incline at constant velocity. The incline makes an angle of $\theta=40^{\circ}$ with respect to the horizontal, as shown in the figure (see Fig. 8). What is the coefficient of kinetic friction between the block and the incline? (Please show your work.)

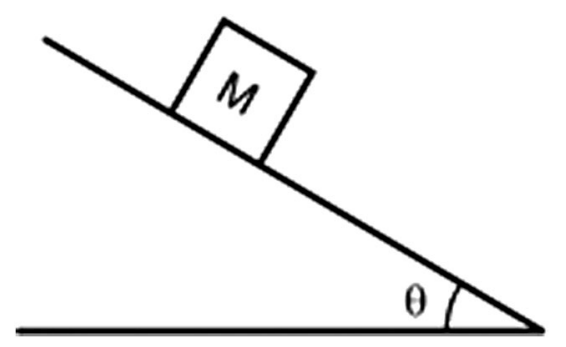

FIG. 8. Figure for friction post-test problems 4-5.

(5) In the preceding question, suppose the mass of the block is doubled, but both the angle and coefficient of friction remain the same (see Fig. 8). Circle the statement below that you feel best describes the motion of the block, and use the space provided to explain why you picked your answer.
(a) The block will still move down the ramp with a constant velocity.
(b) Friction will prevent the block from sliding down the ramp.
(c) The block will accelerate down the ramp, moving faster and faster.

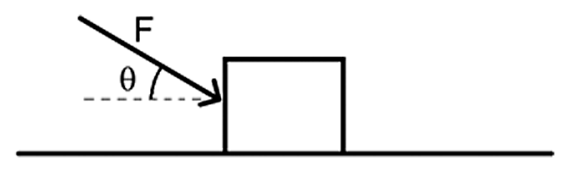

FIG. 9. Figure for friction post-test problem 6.

(6) A box is pushed across a horizontal floor at constant velocity by a force $F=25 \mathrm{~N}$ that makes an angle of $\theta=20^{\circ}$ with the horizontal, as shown in the figure (see Fig. 9). There is friction between the box and the floor.

If the angle $\theta$ were reduced to $10^{\circ}$, what would happen to the speed of the box? Circle the correct statement below, and use the space provided to explain why you picked your answer.

(a) The speed of the box would decrease.

(b) The speed of the box would stay the same.

(c) The speed of the box would increase.

(7) A $M=5 \mathrm{~kg}$ block is connected to a $m=2 \mathrm{~kg}$ block by a massless horizontal string (see Fig. 10). The force $F$ pulls the $2 \mathrm{~kg}$ block to the right across a flat surface. The coefficient of kinetic friction between the blocks and the surface is $\mu_{K}=0.2$. The acceleration of the two blocks is measured to be $1.6 \mathrm{~m} / \mathrm{s}^{2}$.

What is the tension in the string? (Please show your work.)

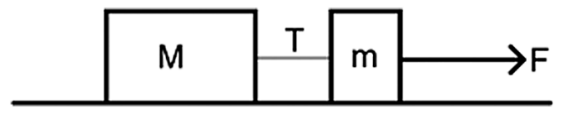

FIG. 10. Figure for friction post-test problem 7.

(8) [The following two questions refer to the same physical situation.] A box of mass $5 \mathrm{~kg}$ sits on the horizontal top of a cart of mass $20 \mathrm{~kg}$ (see Fig. 11). The wheels of the cart roll freely (without friction) on a level floor. The coefficient of static friction between the box and the cart is $\mu_{S}=0.4$. You begin to push the cart with a constant horizontal force.

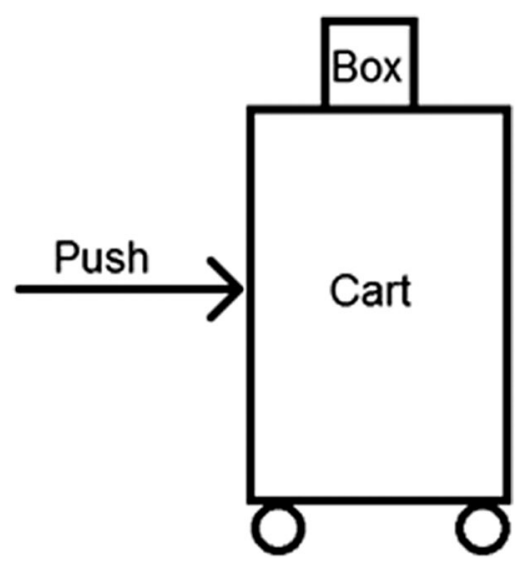

FIG. 11. Figure for friction post-test problems 8-9. 
What is the maximum value of the force you can push with for which the box does not slip on the cart? (Please show your work.)

(9) Now suppose that there is no friction between the box and the cart and that both are initially at rest with the box on top of the cart (see Fig. 11). You start pushing the cart with a constant horizontal force of $150 \mathrm{~N}$. What is the acceleration of the box right after you start pushing the cart? (Please show your work.)

(10) [The following two questions refer to the same physical situation.] There is a block of mass $M$ on the slope that makes an angle $\theta=30^{\circ}$ to the horizontal (see Fig. 12). The coefficient of static friction is 0.7 . The block is stationary on the slope. What is the magnitude of the friction force? Please select the correct answer and show your work in the space provided.
(a) $M g \cos 30^{\circ}$
(b) $0.7 \mathrm{Mg} \cos 30^{\circ}$
(c) $M g \sin 30^{\circ}$

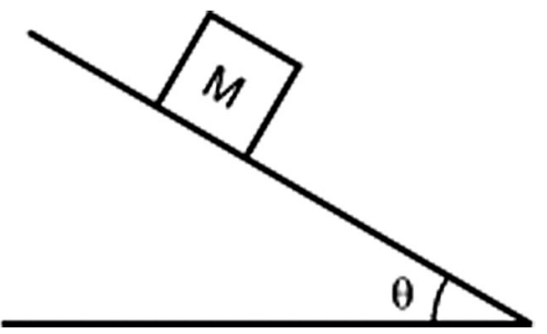

FIG. 12. Figure for friction post-test problems 10-11.

(11) How large can the angle $\theta$ be before the block starts to slip? (Please show your work.)

(12) A truck is accelerating up a hill that is inclined at an angle $\theta$ with respect to the horizontal (see Fig. 13). A crate of mass $m$ is in the bed of the truck and friction keeps it from slipping. Draw a free-body diagram for the crate.

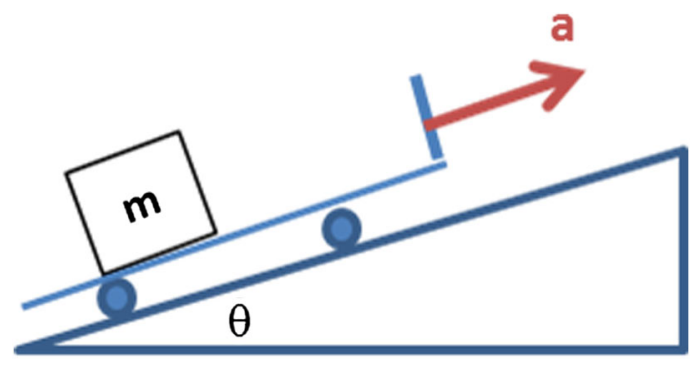

FIG. 13. Figure for friction post-test problem 12 .

\section{APPENDIX B: NEWTON'S LAWS POST-TEST}

This post-test was used with clinical trial 3 (see Table I).

(1) Two blocks having masses $M_{1}=5 \mathrm{~kg}$ and $M_{2}=$ $6 \mathrm{~kg}$ are stacked on the floor of an elevator as shown below (see Fig. 14). The elevator has an upward acceleration of magnitude $a=4 \mathrm{~m} / \mathrm{s}^{2}$.

What is the magnitude of the force that the floor exerts on $\mathrm{M}_{2}$ ?

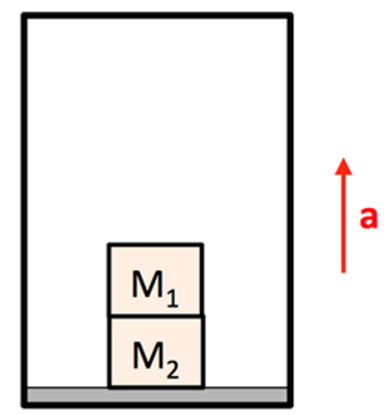

FIG. 14. Figure for Newton's laws post-test problem 1.

(2) A small and a large block (mass $M$ and $2 M$, respectively) are arranged on a horizontal surface as shown in the figure (see the Fig. 15). A student pushes on the left side of the small block so that the entire system accelerates to the right. How does the net force on the small block $F_{S}$ compare to the net force on the large block $F_{L}$ ?

(A) $F_{S}>F_{L}$

(B) $F_{S}=F_{L}$

(C) $F_{S}<F_{L}$

Please explain your answer in the space below.

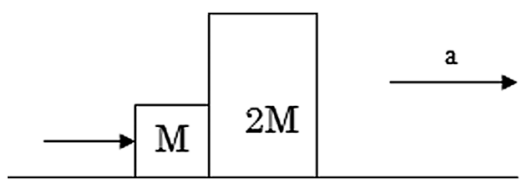

FIG. 15. Figure for Newton's laws post-test problem 2.

(3) Suppose a box having weight $W$ sits on the floor of an elevator that is moving downward with constant velocity $V$. How does the magnitude of $F_{N}$, the normal force exerted by the elevator floor on the box, compare to $W$ ?
(A) $F_{N}>W$
(B) $F_{N}=W$
(C) $F_{N}<W$

Please explain your answer in the space below.

(4) [The following three questions refer to the same physical situation.] Two blocks, one of mass $m$ and the other of mass $2 m$ are connected to opposite ends 
of a string via a pulley, as shown in the figure (see Fig. 16). The block of mass $2 m$ sits on a horizontal frictionless table, and the block of mass $m$ hangs vertically, with gravity pointing downward. The system is released from rest. How does the tension in the string, $T$, compare to $m \cdot g$ ?
(A) $T>m \cdot g$
(B) $T=m \cdot g$
(C) $T<m \cdot g$

Please explain your answer in the space below.

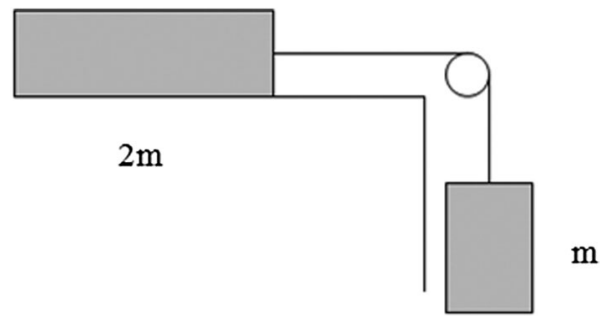

FIG. 16. Figure for Newton's laws post-test problems 4-6.

(5) What is the magnitude of the acceleration of the blocks? Please show your work.

(6) Let the acceleration found in the last question be represented by $a_{\text {old }}$. Suppose now that the two blocks are interchanged (so that the block of mass $m$ sits on the horizontal frictionless table, and the block of mass $2 m$ hangs vertically). The magnitude of the acceleration now is $a_{\text {new }}$. Which of the following is true?

(A) $a_{\text {old }}>a_{\text {new }}$

(B) $a_{\text {old }}=a_{\text {new }}$

(C) $a_{\text {old }}<a_{\text {new }}$

Please explain your answer in the space below.

(7) A ball of mass $M$ is suspended vertically from the end of a string. The other end of the string is attached to the ceiling of an elevator, as shown in the figure (see Fig. 17). The elevator is initially moving

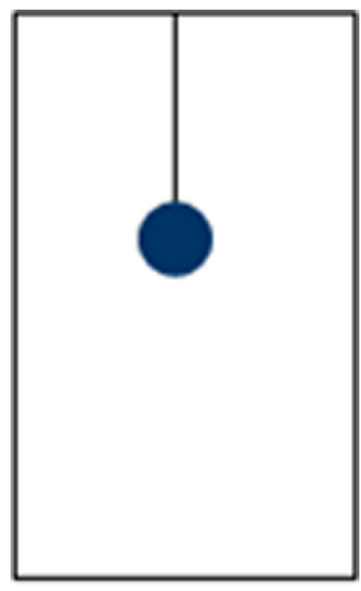

FIG. 17. Figure for Newton's Laws post-test Problem 7. downward at constant speed. Just before reaching the bottom floor, the elevator slows down. As it is slowing down, the tension in the string will be

(A) greater than $M \cdot g$

(B) equal to $M \cdot g$

(C) less than $M \cdot g$

Please explain your answer in the space below.

(8) A block of mass $10 \mathrm{~kg}$ is sitting on a horizontal frictionless surface and is pulled with a rope that makes an angle of $30^{\circ}$ with the horizontal, as shown in the figure (see Fig. 18). The tension in the rope is $20 \mathrm{~N}$.

Let the weight of the block be denoted by $W$. How does the normal force $F_{N}$ compare with $W$ ?
(A) $F_{N}>W$
(B) $F_{N}=W$
(C) $F_{N}<W$

Please explain your answer in the space below.

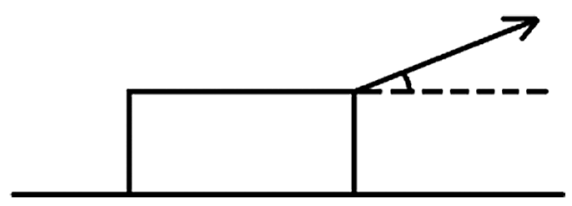

FIG. 18. Figure for Newton's Laws post-test Problem 8.

(9) [The following two questions refer to the same physical situation.] Block $A$ of mass $3 \mathrm{~kg}$ and block $B$ of mass $7 \mathrm{~kg}$ are attached to each other by a string. The two blocks are sitting on a horizontal frictionless surface. Another string is attached to block $B$ and the whole system is pulled to the right so that both blocks accelerate together, as shown in the figure (see Fig. 19). If the tension $T$ is $30 \mathrm{~N}$, what is the tension $T_{1}$ in the string connecting the two blocks? Please show your work.

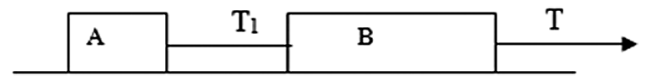

FIG. 19. Figure for Newton's Laws post-test Problem 9.

(10) In the preceding problem, suppose the order of the two blocks is reversed so that block $A$ is in front and block $B$ is in back, as shown in the figure (see Fig. 20), with the same tension $T=30 \mathrm{~N}$. Compared to the preceding problem, the tension $T_{1}$ is now

(A) greater than it was before

(B) the same as it was before

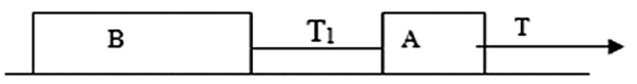

FIG. 20. Figure for Newton's Laws post-test Problem 10. 
(C) less than it was before

Please explain your answer in the space below.

(11) [The following two questions refer to the same physical situation.] An astronaut of mass $220 \mathrm{~kg}$ is floating in the void of space repairing a small satellite of mass $550 \mathrm{~kg}$. After she has finished the repairs she gives the satellite a push of $F=50 \mathrm{~N}$.

During the push, what is the magnitude of the acceleration of the astronaut? Please show your work.
(12) During the push, which of the following statements best describes the magnitude of the acceleration of the satellite?

(A) It is smaller than the magnitude of the acceleration of the astronaut.

(B) It is equal to the magnitude of the acceleration of the astronaut.

(C) It is greater than the magnitude of the acceleration of the astronaut.

Please explain your answer in the space below.
[1] B. S. Bloom, Learning for mastery, Evaluation Comment 1, 1 (1968).

[2] F. S. Keller, Good-bye, Teacher, Journal of applied behavior analysis 1, 79 (1968).

[3] M. Carrier and H. Pashler, The influence of retrieval on retention, Mem. Cogn. 20, 633 (1992).

[4] F. M. Zaromb and H. L. Roediger, The testing effect in free recall is associated with enhanced organizational processes, Mem. Cogn. 38, 995 (2010).

[5] H. L. Roediger, III and J. D. Karpicke, The power of testing memory: Basic research and implications for educational practice, Perspect. Psychol. Sci. 1, 181 (2006).

[6] P. Black and D. Wiliam, Assessment and classroom learning, Assessment in Education: Principles, Policy \& Practice 5, 7 (1998).

[7] J. A. Kulik, K. Carmichael, and C.-L. Kulik, The Keller plan in science teaching, Science 183, 379 (1974).

[8] J. A. Kulik and C.-L. Kulik, Effectiveness of the personalized system of instruction, Eng. Educ. 66, 228 (1975).

[9] J. H. Block and R. B. Burns, Mastery learning, Rev. Res. Educ. 4, 3 (1976).

[10] J. A. Kulik, C.-1. C. Kulik, and P. A. Cohen, A metaanalysis of outcome studies of Keller's Personalized System of Instruction, Am. Psychol. 34, 307 (1979).

[11] T. R. Guskey and S. L. Gates, A synthesis of research on group-based mastery learning programs, https://eric.ed .gov/?id=ED262088.
[12] R. E. Slavin, Mastery Learning reconsidered, Rev. Educ. Res. 57, 175 (1987).

[13] C.-L. C. Kulik, J. A. Kulik, and R. L. Bangert-Drowns, Effectiveness of Mastery Learning programs: A metaanalysis, Rev. Educ. Res. 60, 265 (1990).

[14] G. Gladding, B. Gutmann, N. Schroeder, and T. Stelzer, Clinical study of student learning using Mastery Style versus immediate feedback online activities, Phys. Rev. ST Phys. Educ. Res. 11, 010114 (2015).

[15] E. F. Redish and D. Hammer, Reinventing college physics for biologists: Explicating an epistemological curriculum, Am. J. Phys. 77, 629 (2009).

[16] E. F. Redish, B. W. Dreyfus, B. D. Geller, V. Sawtelle, J. Svoboda, and C. Turpen, Developing a Research-Based Interdisciplinary Physics Course for Biologists, 2012, Proceedings of the AAPT National Meeting, Philadelphia, PA, July 28-Aug 3, 2012.

[17] E. F. Redish and T. J. Cooke, Learning each other's ropes: Negotiating interdisciplinary authenticity, CBE Life Sci. Educ. 12, 175 (2013).

[18] E. F. Redish et al., NEXUS/Physics: An interdisciplinary repurposing of physics for biologists, Am. J. Phys. 82, 368 (2014).

[19] B. O'Shea, L. Terry, and W. Benenson, From $F=m a$ to flying squirrels: curricular change in an introductory physics course, CBE Life Sci. Educ. 12, 230 (2013). 